El Partido Comunista en el Movimiento Obrero Unificado: una alianza con el sindicalismo peronista (1959-1960)

Ezequiel Patricio Murmis

páginas / año 13 - n 32 Mayo-Agosto / ISSN 1851-992X/ 2021

http://revistapaginas.unr.edu.ar/index.php/RevPaginas

DOI: $10.35305 /$ rp.v13i32.503

\title{
El Partido Comunista en el Movimiento Obrero Unificado: una alianza con el sindicalismo peronista (1959-1960)
}

\author{
The Communist Party in the Unified Labor Movement: an alliance \\ with the Peronist syndicalism (1959-1960)
}

\author{
Ezequiel Patricio Murmis \\ Universidad de Buenos Aires, \\ Consejo Nacional de Investigaciones Científicas y Técnicas, \\ Instituto de Historia Argentina y Americana "Dr. Emilio Ravignani” (Argentina) \\ e.murmis@hotmail.com \\ https://orcid.org/0000-0002-8316-4021
}

\begin{abstract}
Resumen
En el presente artículo se analizan las características que asumió la intervención del Partido Comunista de la Argentina (PC) en el "Movimiento Obrero Unificado" (MOU), un agrupamiento sindical que reunió entre 1959 y 1960 a peronistas, comunistas e independientes. En el marco de la reaparición del sindicalismo comunista como un sector insoslayable del movimiento obrero, se estudian las condiciones que hicieron posible el encuentro de diversos sectores de la clase obrera organizada estableciendo relaciones entre el contexto de mutación del modelo de acumulación, el auge represivo del gobierno de Arturo Frondizi, la situación particular del movimiento obrero y los lineamientos políticos y fundamentos programáticos de la acción partidaria del comunismo.

Para llevar a cabo este trabajo desde la óptica comunista se utilizan las publicaciones partidarias del PC como el diario La Hora (LH), el semanario Nuestra Palabra (NP) y la revista teórica mensual Nueva Era (NE); y los documentos disponibles en el "Archivo del Sindicalismo Argentino - Senén González" de la Biblioteca de la Universidad Torcuato Di Tella (ASASG - UTDT).
\end{abstract}

\section{Palabras Clave}

Partido Comunista; Movimiento Obrero Unificado; Sindicalismo Peronista; Movimiento de Unidad y Coordinación Sindical; 62 Organizaciones.

\begin{abstract}
This article aims to analyze the characteristics that assumed the intervention of the Argentine Communist Party (PC) in the " Unified Labor Movement », a union alliance that brought together Peronists, Communists and Independents between 1959 and 1960. In the context of the reappearance of communist unionism as an unavoidable sector of the labor movement, we study the conditions that made possible the meeting of various sectors of the organized working class, establishing links between the mutation of the accumulation model, the increasing repression of the Arturo Frondizi's government, the particular situation of the labor movement and the political and programmatic guidelines of communism.
\end{abstract}

Esta obra está sujeta a la Licencia Reconocimiento-NoComercial-CompartirIgual 4.0 Internacional de Creative Commons. http://creativecommons.org/licenses/by-nc-sa/4.0/ 


\section{Ezequiel Patricio Murmis}

To carry out this work from the communist point of view, the documents used include the partisan publications of the PC, such as the newspaper La Hora (LH), the weekly newspaper Nuestra Palabra (NP) and the monthly theoretical magazine Nueva Era (NE); and the documents available in the "Archive of Argentine Unionism - Senén González" of the Library of the Torcuato Di Tella University (ASASG - UTDT).

\section{Keywords}

Communist Party; Unified Labor Movement; Peronist Syndicalism; Unity and Union Coordination Movement; 62 Organizations.

\section{Introducción}

El objetivo de este artículo es analizar las características que asumió la intervención del Partido Comunista de la Argentina (PC) en el "Movimiento Obrero Unificado" (MOU), un agrupamiento sindical que reunió entre 1959 y 1960 a peronistas, comunistas e independientes. Buscando comprender las condiciones de posibilidad de este acercamiento desde la óptica comunista, se establecerán relaciones con los fundamentos programáticos y los lineamientos políticos coyunturales del partido en un contexto signado por la mutación del modelo de acumulación (Peralta Ramos, 1973), la intervención de la CGT -decretada en 1955 y prolongada hasta 1963-, el avance represivo del gobierno radical intransigente de Arturo Frondizi mediante la declaración del estado de sitio y la aplicación del Plan CONINTES en 1958 (Chiarini y Portugheis, 2014) y la derrota del movimiento obrero (James, 2010). Ello se encuadra en un proceso que venimos demostrando en los avances de investigación, signado por la reaparición del sindicalismo comunista como un sector insoslayable del movimiento obrero entre 1955 y 1960 (Murmis, 2018 y 2020).

El PC caracterizó en el VIIIo Congreso partidario de 1928 la estructura socioeconómica argentina como un capitalismo deformado por la dependencia con el imperialismo, el latifundio y los resabios semifeudales, cuya superación podría lograrse mediante una revolución democrático-burguesa, agraria y antiimperialista. Ese planteo tomó una nueva forma con la adopción del frente popular en 1935, una línea que persistió en las décadas siguientes con adecuaciones coyunturales (Camarero, 2014). A partir de 1955, el PC insistió en la necesidad de conformar un Frente Democrático Nacional antioligárquico, antiimperialista y pro paz con sectores democráticos y progresistas del país, para la formación de un Gobierno de coalición democrática, una orientación que asumió aspectos particulares durante la presidencia de Frondizi en función de la configuración de la lucha de clases y la situación específica de las organizaciones sindicales. En base a ello, en este escrito se pretende demostrar que el PC actuó a fines del '50 siguiendo una política de acercamiento al peronismo que se materializó en las organizaciones obreras en el MOU, luego de la experiencia en la Comisión Intersindical y las 62 Organizaciones de 1957-1958 (Murmis, 2018).

Explorar las características del encuentro entre peronistas y comunistas en el MOU implica, por un lado, cubrir un vacío historiográfico en tanto la producción acerca 


\section{El Partido Comunista en el Movimiento Obrero Unificado: una alianza con el sindicalismo peronista (1959-1960)}

del mismo es escasa, aun contando con los aportes de Tortti (2012) en su estudio de la publicación Soluciones. Existen apenas referencias generales al MOU en los trabajos de largo alcance sobre el movimiento obrero argentino (Senén González, 1971; Rotondaro, 1971; Zorrilla, 1974), en aquellos centrados en los conflictos laborales de la segunda mitad del siglo XX (Acha, 2008; James, 2010; Salas, 1990; Schneider, 2005) y en un libro dedicado a la historia de la juventud comunista (Gilbert, 2009). Por otro, permite revisar alguna de las ideas sobre las que se estructura la investigación en torno al surgimiento de una "nueva izquierda" en la historia reciente argentina. ${ }^{1}$ En ese sentido, se busca cuestionar la hipótesis que afirma que, tras el golpe de Estado de 1955 contra el gobierno de Juan D. Perón, se abrió un proceso de revisión y reevaluación de la experiencia peronista por parte de las nacientes organizaciones políticas y culturales de izquierdas durante los años '60 y '70 que se produjo al margen de la llamada "izquierda tradicional", de la cual el PC es uno de los principales representantes (Altamirano, 2001). Como veremos, la participación comunista en el MOU muestra que el PC no fue ajeno a dicha situación revisionista, razón por la cual entendemos que, en el análisis del surgimiento de la "nueva izquierda", la dimensión programática del partido se revela como el aspecto central a poner en tensión, relegando la influencia de la "cuestión del peronismo". ${ }^{2}$ Buscaremos avanzar en el conocimiento de este capítulo de la historia del movimiento obrero argentino y de las izquierdas a partir de una exposición que recupera, en la primera parte de este trabajo, la división de las 62 Organizaciones y el surgimiento del agrupamiento liderado por el sindicalismo comunista: el Movimiento de Unidad y Coordinación Sindical (MUCS). En una segunda parte se analizan los factores que posibilitaron la concreción de esta acción conjunta durante 1959, destacando la situación general de una derrota del movimiento obrero en la conflictividad social y los posicionamientos de los nucleamientos sindicales. Por último, se analizan las características que asumió la breve experiencia del MOU entre su nacimiento a mediados de 1959 y su disolución tras las elecciones legislativas de 1960. Para llevar a cabo este trabajo desde la óptica comunista se utilizan las publicaciones partidarias del PC como el diario La Hora (LH), el semanario Nuestra Palabra (NP) y la revista teórica mensual Nueva Era (NE); y los documentos disponibles en el "Archivo del Sindicalismo Argentino - Senén González" de la Biblioteca de la Universidad Torcuato Di Tella (ASASG - UTDT).

\section{La división en el movimiento obrero: entre las 62 Organizaciones y el surgimiento del Movimiento de Unidad y Coordinación Sindical (MUCS)}

\footnotetext{
${ }^{1}$ El desarrollo más sistemático del concepto corresponde a María Cristina Tortti (2014), que lo define de un modo amplio como un movimiento social o un actor político con una heterogénea y potente fuerza renovadora compuesta por diversos grupos provenientes del peronismo, las izquierdas, el catolicismo y el nacionalismo, que puede analizarse a partir de una unidad "de hecho" coaligada en base a un lenguaje compartido y un estilo político común en la crítica al sistema

2 Recientemente Rupar (2018) publicó un trabajo que comparte esta perspectiva.
} 


\section{Ezequiel Patricio Murmis}

El apoyo brindado por el grueso de movimiento peronista y el PC a la candidatura de Arturo Frondizi en las elecciones de febrero de 1958 no significó la esperada derrota del continuismo, es decir, de la política de la autodenominada "Revolución Libertadora (1955-1958). ${ }^{3}$ Si bien asumió otorgando una serie de concesiones hacia el movimiento obrero, ${ }^{4}$ la implementación del programa desarrollista a partir del establecimiento de acuerdos con capitales extranjeros para la explotación de petróleo en territorio nacional, el acuerdo con el Fondo Monetario Internacional (FMI) y el "Plan de Estabilización Económica", así como la aprobación de la enseñanza "libre", quebró rápidamente el frente que se había formado de hecho detrás de su candidatura (Rodríguez Lamas, 1984).

En materia sindical, el acuerdo establecido en secreto entre radicales intransigentes y la cúpula del peronismo referente a la recuperación del modelo sindical imperante entre 1945 y 1955 mediante la sanción de una nueva ley de Asociaciones Profesionales, sentó las bases para una convivencia entre el gobierno de Frondizi y las 62 Organizaciones durante 1958 que no sólo se alteró en pocos meses, sino que reavivó la lucha por la conducción del movimiento obrero. La nueva división producida en ese año, luego de los acercamientos impulsados durante la "Revolución Libertadora", presentaba un rasgo significativo: la reaparición del sindicalismo comunista como un sector insoslayable en las organizaciones sindicales (Murmis, 2018 y 2020).

La coincidencia entre comunistas y peronistas no se redujo a la opción por el mismo candidato en las elecciones presidenciales, sino que venía construyéndose al calor de la experiencia conjunta en el movimiento obrero de 1957. La resistencia en los sindicatos -que diagramó un nuevo y complejo mapa del movimiento obrero cruzado entre viejas y nuevas camadas dirigentes, posiciones "duras" y "blandas" y, finalmente, habitado por sectores heterogéneos revitalizados con la suspensión de la hegemonía peronista (James, 2010; Salas, 1990; Schneider, 2005)- encontró a ambos sectores peleando en la Comisión Intersindical primero y luego en las nacientes 62 Organizaciones por la liberación de presos, el levantamiento del estado de sitio, la derogación de leyes represivas, un mejoramiento de las condiciones de vida de la clase trabajadora y la normalización de la CGT. ${ }^{5}$ Estos dos organismos intergremiales que expresaron el saldo organizativo de la clase obrera en la Resistencia presentaron, además de la similitud en sus programas y de los sectores que los integraban, una diferencia fundamental: mientras el signo característico de

\footnotetext{
3 "La gran tarea de la hora es derrotar el continuismo" $N E$, año X, nำ1, enero 1958

${ }^{4}$ Entre las principales medidas se encuentran la derogación de la ley de residencia de 1902, de los decretos de 1956 de la "Revolución Libertadora" referentes a la prohibición de propaganda y símbolos peronistas y de inhabilitación para ejercer cargos gremiales; el otorgamiento de un aumento del $60 \%$ sobre las remuneraciones fijadas el $1^{\circ}$ de febrero de 1956; el levantamiento de las intervenciones sindicales de fines de 1957 y la sanción de una ley de Asociaciones Profesionales de acuerdo al modelo de organización sindical estructurado durante el peronismo.

${ }^{5}$ Se pueden consultar los programas en "La lucha por la unidad de la clase obrera" de Vicente Marischi. $N E$, año IX, no 5, pp 8-12 y "Llamamiento a reforzar el estado de alerta de todos los gremios del país", $N P$ no $383,10 / 10 / 57$, p. 4.
} 


\section{EI Partido Comunista en el Movimiento Obrero Unificado: una alianza con el sindicalismo peronista (1959-1960)}

la primera fue la organización por parte del sindicalismo comunista, en la segunda, la dirección pasó a ser ejecutada por el sindicalismo peronista en la medida en que se fue fortaleciendo al calor de las normalizaciones sindicales durante 1957. Si bien el PC fue una de las fuerzas centrales en la reorganización del movimiento obrero, el peronismo logró ponerse a la cabeza de aquel proceso organizacional, mostrando así que la medida del crecimiento del peronismo organizado en los sindicatos fue en sintonía con la pérdida de influencia del sindicalismo comunista en el movimiento obrero (Murmis, 2018).

La acción conjunta entre estos dos sectores durante 1957 se quebró en los primeros meses de 1958 con la asunción de Frondizi. Tal como se conoció más adelante, el triunfo en las elecciones había contado con la fuerza del peronismo luego de acordar una serie de medidas, entre las que se encontraban el levantamiento de las inhabilitaciones, la normalización de los sindicatos y de la CGT y la realización de elecciones con interventores (Rodríguez Lamas, 1985). En ese sentido, la sanción de una nueva ley de Asociaciones Profesionales basada en el modelo de organización sindical de los años peronistas fue la herramienta para cumplir el pacto. Sancionada el 8 de agosto de 1958 en reemplazo de las modificaciones realizadas por el gobierno de Aramburu, tendientes a la atomización de la organización gremial (Zorrilla, 1974; 71), la ley abolía la representación de la minoría en el sindicato, reconocía a las organizaciones que nuclearan a trabajadores y trabajadoras por actividad o por oficio (art. 3), obteniendo la personería gremial aquella más representativa (art. 18): es decir, restablecía el modelo peronista de sindicato único con derechos de negociación. Además de estas organizaciones de primer grado, reconocía a las federaciones que agruparan a éstas y a la confederación que reuniera a las federaciones (art. 4). Si bien la cuestión de la posibilidad de agremiarse por oficio revistió críticas por parte del PC por su carácter “divisionista” (Marischi, 1958; 11), el principal punto de conflicto estuvo en el proceso de reglamentación de la ley, que ordenaba desde el Ejecutivo la renovación de autoridades en un lapso de 90 días (art.57).6

Esta disposición fue aquella que desató las discrepancias latentes en el movimiento obrero en general y en las 62 Organizaciones en particular, que se fracturaron en torno al problema de la intervención estatal en los sindicatos. Mientras los sectores peronistas de "las 62" apoyaban la declaración del estado de asamblea y la realización de nuevas elecciones en los sindicatos, ${ }^{7}$ el sindicalismo comunista se mantuvo en contra de la participación de interventores en una cuestión privativa de los trabajadores como lo son las elecciones de su gremio. Ello se acompañaba con el rechazo a un proceso eleccionario que demoraría la elaboración y discusión de convenios colectivos tras varios años sin negociación colectiva en numerosos sindicatos, una cuestión que se hizo efectiva con la prórroga del decreto 824 de la "Revolución Libertadora", que implicaba la postergación de la negociación colectiva

\footnotetext{
${ }^{6}$ Ley 14455. Honorable Congreso de la Nación Argentina. 8 de agosto de 1958.

7 "Para llevar a cabo el programa de las 62 presentado a Frondizi" LH, 27/3/58, p.6
} 


\section{Ezequiel Patricio Murmis}

-suspendida desde 1954- hasta el $1^{\text {o }}$ de diciembre de $1958 .{ }^{8}$ El meollo del asunto estribaba en que, no sólo se rompía el programa de "las 62" al solicitar una nueva intervención estatal, sino también en la presión que ejercía el sindicalismo peronista para conquistar la CGT e imprimirle su signo político (Marischi, 1958). Esta disputa se aceleró cuando se anunció oficialmente que el nuevo interventor de la CGT, Alfredo Insaurralde, encabezaría la normalización de los sindicatos mediante la declaración de 'estado de asamblea' en todos los gremios y la realización de nuevas elecciones con veedores estatales. ${ }^{9}$

Por esa razón, el sindicalismo comunista junto a otras direcciones opositoras a este proceso -la mayoría perteneciente a las 62 Organizaciones- lanzaron un documento firmado por 19 organizaciones denunciando la acción de un núcleo de dirigentes que llamaba a la intervención del Estado en nombre del conjunto de "las 62". ${ }^{10}$ Ese nuevo grupo tomó como nombre la cantidad de sindicatos que firmaron el documento en discrepancia con la ley, independientemente del número de organizaciones que participaron en él con el desarrollo de los acontecimientos. Se trató, en definitiva, de un agrupamiento de sindicatos compuesto por un núcleo de 13 organizaciones, no todos ellos dirigidos por el PC, que traccionaba alternativamente a otras. ${ }^{11}$ Confluyeron allí por la coincidencia en el reclamo en contra de la intervención estatal en la normalización de las organizaciones, de modo que circunstancialmente se acercaron no solo las que pertenecían y fueron abandonando "las 62" sino también algunas de los 32 Gremios Democráticos e incluso independientes. De este modo, tal como afirmó el dirigente comunista de la madera Vicente Marischi (1958), llegaron a participar 29 organizaciones en total.

\footnotetext{
8 "Reforzar la unidad y la independencia sindical"," $L H 25 / 8 / 58$, p.6

9 "Interventor en la CGT sería el Sr. Insaurralde" $L H, 15 / 5 / 58$, p.1

10 "A los trabajadores y la opinión pública" ASASG-UTDT. C1-538, 00038. Una reproducción de ese documento se encuentra publicado en "No se puede hablar en nombre de las ' 62 ' sin consultar a los gremios adheridos" $L H, 28 / 6 / 58$, p.4. Las 19 Organizaciones firmantes eran: Federación de Sindicatos Unidos Petroleros del Estado; Unión Obrera de la Construcción de la República Argentina - Capital; Unión de Sindicatos de la Industria Maderera de la República Argentina; Federación Obreros Cerveceros y Afines; Sindicato del Seguro; Federación Argentina de Trabajadores de Edificios de Renta y Particulares; Federación Argentina de Trabajadores de la Industria Química; Asociación Argentina de Telegrafistas y Afines; Sindicato Argentino de Músicos; Sindicato Argentino de Prensa; Asociación del Personal Aeronáutico; Asociación de Trabajadores de Barracas, Depósitos Afines al Puerto; Sindicato del Fibrocemento y Afines; Federación de Vendedores de Diarios, Revistas y Afines; Sindicato de Mecánicos y Afines del Transporte Automotor; Unión Obrera Gastronómica (Capital - San Martín), Sindicato de Empacadores de Frutas de Río Negro y Neuquén; Sindicato del Aceite (Capital) y Sindicato de Obreros y Empleados de la Industrial del Papel Cartón y Afines.

11 Sindicato Único Petroleros del Estado; UOCRA - Capital; Unión de Sindicatos de la Industria Maderera de la República Argentina; Federación Argentina de Trabajadores de la Industria Química; Asociación Argentina de Telegrafistas y Afines; Sindicato Argentino de Músicos; Sindicato Argentino de Prensa; Asociación del Personal Aeronáutico; Asociación de Trabajadores de Barracas, Depósitos Afines al Puerto; Federación de Vendedores de Diarios, Revistas y Afines; Sindicato de Mecánicos y Afines del Transporte Automotor; UOG (Capital - San Martín) y el Sindicato de Empacadores de Frutas de Río Negro y Neuquén. Alternativamente participan, además de aquellas originarias 19, la Federación de Empleados de Comercio, la Unión Ferroviaria, La Fraternidad, la Asociación de Trabajadores del Estado, Empleados del Caucho, la Unión Personal Civil de la Nación, la Federación de Luz y Fuerza y Asociación Bancaria
} 


\section{El Partido Comunista en el Movimiento Obrero Unificado: una alianza con el sindicalismo peronista (1959-1960)}

"Las 19" transcurrieron sus primeros meses como agrupamiento sindical presentando un memorial en el Congreso, ${ }^{12}$ un proyecto con reformas para limitar la intervención estatal en los sindicatos ${ }^{13}$ y expresando su posición ante el mismo Frondizi ${ }^{14}$ sin lograr su cometido. También organizaron una manifestación en las calles el 14 de agosto contra la carestía de vida en la que participaron 18 federaciones y 21 sindicatos. ${ }^{15}$ A su vez, se sumaron al paro convocado por "las 62" el 10 de octubre contra la carestía de vida, aunque con distintas consignas. Finalmente, el grupo de "las 19" resolvió constituirse como Movimiento de Unidad y Coordinación Sindical (MUCS) a fines de diciembre de 1958, es decir como una comisión cuyo propósito era "promover un movimiento de unidad y coordinación sindical" en base a un programa inmediato. Esto implicaba para sus integrantes un mayor compromiso en la lucha por la unidad, en el marco de un movimiento obrero dividido y desorganizado. Si en sus orígenes "las resoluciones que adoptaran los gremios antiintervencionistas no eran obligatorias para estos", el objetivo de esta nueva comisión era "sentar las bases de la unidad de los trabajadores argentinos". En ese sentido, la comisión integrada por delegados de los gremios mercantil, bancario, madera, gastronómico, construcción, prensa y ferroviario de La Fraternidad, definió en tres puntos su guía de acción: la lucha contra la carestía de vida; la desmovilización de los ferroviarios y la inmediata liberación de los detenidos; y el levantamiento del estado de sitio. ${ }^{16}$ A este programa inmediato se le sumaban otros puntos como la normalización sindical y la recuperación de la CGT; la negociación de convenios colectivos que contemplen las aspiraciones obreras; y la oposición a todo plan económico tendiente a descargar la crisis sobre la clase trabajadora. ${ }^{17}$

\section{9: la derrota como factor de unidad}

La acumulación de derrotas en los principales conflictos llevados a cabo entre noviembre de 1958 y mediados de 1959, pusieron en el centro de escena la debilidad de un movimiento obrero dividido ante la ofensiva represiva del gobierno de Frondizi. En ese marco, el año 1959 presentó algunos factores que promovieron la nueva alianza entre peronistas y comunistas en el llamado Movimiento Obrero Unificado (MOU): en primer lugar, con la privatización de la explotación petrolera y el anuncio del plan económico se quebró la tregua otorgada al gobierno por el sindicalismo peronista en 1958. Eso se reflejó a fines de enero de 1959 con el cambio de la Mesa Directiva de "las 62", que pasó a estar integrada por delegados del interior

\footnotetext{
12 "Memorial de los gremios antiintervencionistas a Diputados y Senadores" $L H$ 3/7/58, pp. 1 y 5

13 "Hoy: Antiintervencionistas en la Cámara de Diputados" LH 15/7/58, p.5

14 "Delegados obreros rechazan la ley de intervención estatal" $L H$ 26/8/58, pp. 1 y 7

15 "Hacer pagar la crisis a los ricos es el camino para detener la carestía" $N P$ no 427, 14/8/58, p.1

16 Las citas pertenecen al artículo "Se disuelven las "19" como tales: paso hacia la unificación obrera" LH 28/12/58, p.7.

17 "Bases para el entendimiento" $L H, 6 / 1 / 59$, p.6
} 


\section{Ezequiel Patricio Murmis}

y sindicatos pequeños ligados a posiciones "duras" tras la toma del frigorífico "Lisandro de la Torre" (James, 2010; 163; Salas, 1990; Gazzera y Ceresole, 1970). Relacionado a ello, las elecciones sindicales realizadas bajo la renovada ley de Asociaciones Profesionales no arrojaron los resultados deseados para el sindicalismo peronista: si bien en los años siguientes la nueva ley sirvió a la consolidación de ese sector, no es menos cierto que tras las elecciones de 19581959, no solo la joven camada peronista derrotó en varios sindicatos a los antiguos jerarcas (Senén González, 1971) sino que también una veintena de organizaciones ratificaron la existencia del MUCS como un polo ineludible en el movimiento obrero (Zorrilla, 1974; Murmis, 2020). En tercer lugar, el pico de jornadas laborales perdidas alcanzado ese año a pesar de la baja de la cantidad de huelgas es un indicador tanto de la combatividad obrera como de la intransigencia del gobierno y de los sectores del capital para acceder a las demandas (James, 2010; Schneider, 2005). Finalmente, a la proscripción del peronismo se añadió la ilegalización del PC en abril de 1959, situación que los emparentó al encontrarse marginados a menos de un año de las elecciones legislativas a realizarse en marzo de 1960.

La aplicación del programa desarrollista fue encarada con determinación por el gobierno a fines de 1958, cuestión que se evidenció en su enfrentamiento con los sindicatos de dos sectores estratégicos: tanto la huelga del Sindicato Unido de Petroleros del Estado (James, 2010; Schneider, 2005) como la de la Unión Ferroviaria (Sánchez, 2018) culminaron con la movilización militar del personal, centenares de detenciones, la declaración del estado de sitio y la aplicación secreta del Plan CONINTES. ${ }^{18} \mathrm{El}$ alza de la conflictividad encontraba un límite en la falta de coordinación de las acciones, a pocos meses de producido el alejamiento de "las 19" y con unas "62" que buscaban suavizar el enfrentamiento con el gobierno.

La política unitaria enarbolada por el PC a nivel nacional, sintetizada en la apuesta por crear un Frente Democrático Nacional antioligárquico, antiimperialista y pro paz con los sectores democráticos y progresistas del país, tenía su correlato en la intervención en los sindicatos. La orientación que seguían en el movimiento obrero se basaba en tres pilares conectados entre sí: la lucha por la unidad de la clase obrera organizada en sindicatos, federaciones nacionales por industria y una única central; la organización independiente del Estado y la patronal; y la apuesta por hacer del Partido Comunista el partido del proletariado en su conjunto, mediante una labor esclarecedora de los intereses y la propia fuerza de la clase trabajadora. Consideraban que la delimitación de los intereses obreros y la actuación en unidad serían la garantía para impulsar el curso democrático y progresista del país, lo cual estaba en estrecha relación con el programa partidario (Marischi, 1958).

\footnotetext{
${ }^{18}$ En la primera noche del estado de sitio se procedió a detener a centenares de activistas peronistas y comunistas. Un caso singular fue la detención de 52 comunistas y 25 peronistas en un barco a la deriva sin brindar informaciones sobre el destino. "Desembarcaron a los presos; ahora deben ser liberados" $L H, 24 / 11 / 58$, p.1 y 16. En simultáneo se aplicó de forma secreta el Plan CONINTES a través del decreto 9880 de noviembre 1958. El mismo adquirió carácter público en marzo de 1960 (Chiarini y Portugheis, 2014).
} 


\section{EI Partido Comunista en el Movimiento Obrero Unificado: una alianza con el sindicalismo peronista (1959-1960)}

En las elecciones sindicales de fines de 1958 y principios de 1959 convocadas conforme a la nueva ley de Asociaciones Profesionales, reeditó el planteo sostenido de cara a las mismas elecciones desarrolladas en 1956-1957: la necesidad de conformar listas unitarias en los sindicatos para impedir la división por cuestiones políticas o religiosas. En ese sentido, el PC participó en el armado de listas unitarias en los gremios en los que tenía inserción, buscando no solo revalidar las posiciones conquistadas en 1956-1957 sino obtener nuevos triunfos frente a sus adversarios: los "jerarcas" sindicalistas tanto del peronismo como los nucleados en los 32 Gremios. ${ }^{19}$

Si bien la consigna unitaria en el movimiento obrero formó parte de la política del PC desde la intervención de la CGT, estos sucesos impulsaron al grupo de "las 19" a "disolverse con el fin de no ahondar las divisiones configuradas en nucleamientos como las 32 o 62, y dar lugar a una comisión -de carácter provisional- que tenga por meta sentar las bases de la unidad de los trabajadores argentinos". ${ }^{20}$ La creación del MUCS en medio del alza represiva buscaba establecer acercamientos para impedir la aplicación de la política económica luego de mostrarse las diferencias de acción entre los agrupamientos, fundamentalmente en el conflicto petrolero.

No obstante, la intervención del novel MUCS y de las 62 Organizaciones en la toma del frigorífico "Lisandro de la Torre" en enero 1959 (Salas, 1990) y en conflicto bancario de abril a junio de 1959 (Acha, 2008) volvió a mostrar la falta de coordinación en los agrupamientos. La histórica huelga general y toma del establecimiento por parte de trabajadores y trabajadoras contra la privatización del frigorífico contó con la participación de ambos agrupamientos, aunque el MUCS lo hizo declarando la huelga por 48hs y "las 62" por tiempo indeterminado. El brutal desenlace del conflicto, en un país con estado de sitio, incluyó la declaración de ilegalidad de la huelga, represión, la movilización militar del personal del frigorífico y de Transportes de Buenos Aires, la intervención de los principales sindicatos dirigidos por peronistas (tranviarios, textil, carne y metalúrgico) y comunistas (madera, químicos y construcción), la clausura de locales del PC, el secuestro de sus publicaciones La Hora y Nuestra Palabra. En ese contexto, el PC analizó la huelga destacando la combatividad y resolución obrera para la lucha y señalando el hiato entre la unidad "por abajo" y las diferencias entre dirigencias sindicales. De ese modo, la conclusión fue que "la convicción de la clase obrera sólo podrá lograr el triunfo de sus demandas cuando realice sus luchas organizadamente y cuente, para lograrlo, no con pluralidad de comando, sino un comando único". ${ }^{21}$

El ataque del gobierno contra los principales sindicatos conducidos por peronistas y comunistas propició la realización de un paro nacional en la tarde del 3 de abril convocado conjuntamente por las organizaciones sindicales intervenidas (metalúrgicos, construcción, textiles, carne, madera, petroleros, químicos,

19 "Las elecciones sindicales: de ellas debe salir la unidad y no la división de los trabajadores", $N P \mathrm{n}^{\circ}$ $443,4 / 12 / 58$ p. 4

20 'Se disuelven las '19' como tales: paso hacia la unificación obrera" $L H, 28 / 12 / 58$, p.7

21 "Las lecciones de la gran huelga general..." Op. Cit, p 10. 


\section{Ezequiel Patricio Murmis}

tranviarios, obreros del frigorífico y portuarios de Buenos Aires) en el que reclamaron el levantamiento de intervenciones, la reanudación de la discusión de convenios colectivos y aumento salarial de emergencia, reincorporación de cesantes en el frigorífico y de los despedidos en general, la liberación de los presos y una política de defensa de la industria nacional. ${ }^{22}$ La acción, que contó con la participación del MUCS, "las 62" y sindicatos independientes, terminó con la detención de 138 manifestantes ${ }^{23}$ y la ilegalización del PC a las pocas semanas.

La huelga bancaria y del seguro en la primera mitad del año volvió a evidenciar la diferencia entre la fragmentación de las corrientes sindicales y la solidaridad de las bases, una cuestión que se reveló central para el triunfo de un gobierno decidido a doblegar al gremialismo (Acha, 2008). La reiteración de estos aspectos habilitó la posibilidad de una acción conjunta entre comunistas y peronistas en los sindicatos, la cual se concretó el 17 de agosto en el Movimiento Obrero Unificado. En palabras del maderero comunista Marischi, la huelga bancaria "fue la piedra de toque que facilitó las condiciones para la unidad de acción" (1960; 17) por la valentía y el carácter unitario de la combatividad de las bases, que obtuvieron el apoyo de la clase obrera en el paro general del 15 de mayo. El análisis realizado por el dirigente ponía sobre la mesa la exigencia de la militancia comunista y la acción del MUCS como factores que sirvieron para quebrar la resistencia a la unidad de dirigentes de "las 62", quienes cedieron tras la huelga y constituyeron la Comisión Permanente de Enlace del Movimiento Obrero Unificado.

\section{La breve experiencia del MOU}

La experiencia unitaria que reunió en el MOU a las 62 Organizaciones, el MUCS y sindicatos independientes (la Federación Argentina de Trabajadores de Luz y Fuerza, la Asociación del Personal Aeronáutico y la Asociación Argentina de Telegrafistas, Radiotelegrafistas y Afines) se extendió apenas entre agosto de 1959 y abril de 1960. A la luz de las expectativas que tenían el PC y el MUCS, la misma fue un fracaso en tanto el MOU no se convirtió en el centro dirigente y unificador del proletariado de cara a la formación del Frente Democrático Nacional, antioligárquico y antiimperialista que estructure el gobierno de amplia coalición democrática. ${ }^{24} \mathrm{Si}$ bien el MOU tuvo su presencia tanto en las calles como en la intervención de los conflictos del período, la convivencia entre peronistas y comunistas apenas alcanzó para la coincidencia en el voto en blanco de las elecciones legislativas de 1960.

La carta de presentación del MOU fue la "Declaración de Principios" en contra de la política económica del gobierno, en la que se denunciaba "el plan elaborado por el

\footnotetext{
22 "Paro obrero nacional: viernes 3, a las 16 " $N P \mathrm{n}^{\circ} 457,31 / 3 / 59$, pp. 1 y 4

23 "138 obreros y vecinos presos por ejercer el derecho de reunión" $N P$ n ${ }^{\circ} 459,14 / 4 / 59$, p.7

24 "Declaración del Comité Ejecutivo del Partido Comunista sobre los resultados de las elecciones del 27 de marzo" $N P n^{\circ} 511,12 / 4 / 60$, p.3.
} 


\section{EI Partido Comunista en el Movimiento Obrero Unificado: una alianza con el sindicalismo peronista (1959-1960)}

Fondo Monetario Internacional, aplicado fríamente por sectores oligárquicos y reaccionarios", la entrega de riquezas nacionales a monopolios imperialistas y enunciaba el programa de reivindicaciones compuesto por 13 puntos, que abarcaba desde el levantamiento del estado de sitio, la libre discusión de convenios, el cese de intervenciones y la devolución de la CGT hasta el desarrollo de la industria nacional y la reforma de la estructura latifundista. ${ }^{25} \mathrm{El}$ acuerdo suscripto incluía que los grupos integrantes conservaban su autonomía y estructuras organizativas propias y que la conducción del MOU fuera ejercida por una Comisión Permanente de Enlace integrada por representantes del MUCS, de "las 62" e independientes. ${ }^{26}$

La creación del MOU fue en paralelo a la huelga metalúrgica que se extendió durante mes y medio por aumentos salariales y en contra de la racionalización productiva y de la reglamentación patronal de los órganos de base fabriles. También se produjo en ese tiempo el conflicto textil de similares características entre septiembre y noviembre, finalizando ambos con resoluciones poco beneficiosos de acuerdo a los reclamos obreros (Schneider, 2005). En ese marco, el MOU declaró un paro nacional de $48 \mathrm{hs}$ para los días 23 y 24 de septiembre en solidaridad con los gremios en lucha que contó, según la prensa comunista, con el acatamiento de 4 millones de personas. El gobierno respondió en la víspera del mismo con razzias policiales que llevaron detenidas cerca de un centenar de militantes político-sindicales, entre los que encontraban dirigentes como el comunista Rubens Iscaro (Secretario general de la Construcción), Rodolfo Aráoz Alfaro (apoderado del PC), Andrés Framini (Secretario general de la Asociación Textil), Venido Matheu (Secretario adjunto del Sindicato de Prensa), Luis Trossi (Secretario de organización de la Construcción de Capital), José Luis Cora (Secretario de la juventud peronista), Ricardo Trecarichi (miembro de Mesa del MOU), José Zeballos (ex Secretario general del Transporte), directivos del sindicato metalúrgico como Luciano Pani (Mesa Coordinadora de "las 62") y José Rucci. ${ }^{27}$ El golpe asestado contra la dirigencia del MOU estuvo acompañado de la causa presentada por el gobierno ante la justicia para el desconocimiento de la personería del PC y para su disolución. En ella se acusaba al PC de gestar un plan de perturbación mediante el terrorismo y el sabotaje, ${ }^{28}$ con el objetivo de dejarlo fuera de la contienda electoral de 1960.

En ese contexto el MOU convocó a la realización de su primer -y único- Plenario Nacional para el 6 de noviembre de 1959 con la previa actuación de Plenarios Regionales. El mismo sesionó con la presencia de 212 delegados representantes de 43 asociaciones, 19 delegaciones de regionales de la CGT $^{29}$ y estuvo presidido por una Mesa de Enlace integrada por Jorge Cabrera (aeronáutico), Raúl Oscar Russo (radiotelegrafista), José Miguel Zárate (construcción, que fue detenido a la salida del

25 "Gran triunfo de la unidad obrera: el acuerdo de acción conjunta del MUCS, las "62" y gremios independientes" $N P \mathrm{n}^{\circ} 478,25 / 8 / 59$, pp 1 y 4.

${ }^{26}$ La Razón, 6/11/1959, ASASG-UTDT. C1-553, 00053

27 "Exigencia popular unitaria: ¡libertad a todos los presos político-gremiales! ¡Basta de campos de concentración!" $N P \mathrm{n}^{\circ} 484,6 / 10 / 59$, p. 3

28 "Edificando sobre el fango" $N P \mathrm{n}^{\circ} 484,6 / 10 / 59$, pp. 1 y 3.

${ }^{29}$ Diario La Razón, s/d, ASASG-UTDT. C1-24, 00024 


\section{Ezequiel Patricio Murmis}

Plenario), Radames Grano (comercio), Castillo (vidrio), Juan José Jonsch (telefónico) y Roberto García (caucho) (Tortti, 2012). Allí se ratificó el programa de 13 puntos y resolvió presentar un memorial al Congreso con el acompañamiento de una concentración en la plaza el día 12, reclamando la liberación de los presos, la solución de los conflictos gremiales y la participación de todos los partidos en las elecciones sin discriminación. ${ }^{30}$

Uno de los principales terrenos de lucha del MOU fue el de la defensa de los presos político-gremiales. Se formó una Comisión Jurídica para atender a los detenidos, se realizó una la campaña por las liberaciones y el fin de las detenciones que contó con tres jornadas de solidaridad con los presos el 19, 20 y 21 de noviembre y la realización de un acto en Plaza Once el 15 de diciembre. ${ }^{31}$

El otro de los ejes que estructuró la actividad del MOU fue la campaña por el voto en blanco para las elecciones legislativas del 27 de marzo de 1960. De acuerdo a la investigación de Tortti (2012), el proyecto del semanario Soluciones como vocero del MOU tomó cuerpo precisamente para hacer campaña por el voto blanco. Mientras el PC peleaba en la justicia y juntaba firmas contra la proscripción, ${ }^{32}$ el Consejo Coordinador y Supervisor del Peronismo adelantó en octubre su postura a favor del voto blanco tras la confirmación oficial de la imposibilidad del peronismo para participar de las elecciones. En sintonía con esa postura, "las 62" resolvieron votar del mismo modo en su plenario realizado en diciembre en Rosario, cuestión que fue motivó críticas. ${ }^{33}$

Reproduciendo un conflicto como el de 1958, el MUCS conducido por comunistas reprochó a "las 62" el haber decidido por su cuenta el voto blanco, dado que el MOU había determinado pelear por el levantamiento de las proscripciones con la movilización de masas: es decir, acusó a peronistas de no acatar las resoluciones del Plenario y de haber desestimado la capacidad de la movilización para la conquista de libertades democráticas (Marischi, 1960). No obstante, dado que la lucha por el levantamiento de las proscripciones no prosperaba, el Comité Central del PC hizo su llamado para votar en blanco 34 "porque no quedaba otro camino" (Marischi, 1960; 21). De ahí en más el PC inició la campaña haciendo hincapié en la necesidad de empeñar energías junto a peronistas para la creación de comités de lucha en cada terreno para organizar el voto en blanco contra el fraude y el estado de sitio y por elecciones democráticas. ${ }^{35}$ En paralelo a esa organización "por abajo", el MOU presentó sus reivindicaciones en un memorial al Presidente de cara a las

\footnotetext{
30 "Los gremios se movilizan unidos en la tarea de ejecutar las resoluciones del MOU" NP no 491, 24/11/59, pp. 1 y 4

31 "El acto de anoche en Plaza Once", La Razón, 16/12/59, p.6. ASASG-UTDT C1-555. 00055

32 "En la Capital, la campaña inició el año nuevo con 130.000 firmas" $N P \mathrm{n}^{\circ} 498,12 / 1 / 60$, p.3

33 Documento "62 Organizaciones", 29/12/59, ASASG-UTDT. C1-552, 00052

34 "Llamamiento del C.C. del Partido Comunista a la clase obrera y el pueblo argentino para que voten en blanco el 27 de marzo y luche por la anulación de las elecciones fraudulentas y por la realización de elecciones verdaderamente democráticas" $N E$ año XII, no1, febrero 1960.

35 "Organizar el voto en blanco" $N P n^{\circ} 505,1 / 3 / 60$, p. 1; "La lucha electoral bajo el plan CONINTES" $N E$ año XII, n 3, abril 1960, pp 210-219.
} 


\section{EI Partido Comunista en el Movimiento Obrero Unificado: una alianza con el sindicalismo peronista (1959-1960)}

elecciones ${ }^{36}$ cuya respuesta estuvo acorde a la política represiva de entonces: la ejecución pública del Plan CONINTES en todo el territorio nacional mediante el decreto 2628 del 13 de marzo de 1960 (Chiarini y Portugheis, 2014), en una maniobra que el PC calificó de "golpe militar palaciego" al someter el poder civil al militar. $^{37}$

Finalmente, las elecciones legislativas se realizaron bajo el estado de sitio, con persecuciones políticas y detenciones, proscripciones y con el Plan CONINTES. El voto en blanco ocupó el primer lugar con un 25\% de los sufragios, relegando al segundo lugar por una diferencia de dos puntos a la UCRP y al tercer lugar a la UCRI de Frondizi, que obtuvo un 20\%. El triunfo del voto blanco fue un indicador de la centralidad de la clase obrera en la estructura social del país y del peronismo como su representación política. Si bien el balance del PC ponía en el centro de escena a su propio partido, lo cierto es que el voto blanco fue producto de una alianza entre ambos sectores, con preponderancia del peronismo. El tono triunfalista del análisis posterior, en el que se llamaba a consolidar el MOU y la alianza obrero-campesina, incluía un aspecto que resulta revelador a los fines de lo que se pretende asentar en este escrito: allí se afirmó que los resultados de las elecciones demostraban que la clase obrera estaba en condiciones de conquistar la hegemonía del mentado Frente Democrático Nacional, antioligárquico, antiimperialista y pro paz mediante "la unidad de acción comunista-peronista". ${ }^{38}$

El interés estratégico que el PC depositaba en esta alianza pronto fue quimera con el abandono del MOU a su suerte por parte de "las 62", que definieron en su Plenario Nacional realizado tras las elecciones:

"El MOU representa un momento de nuestra vida gremial y el mismo llenó las necesidades en su oportunidad. [...] Si bien la conformación de la dirección del MOU pudo aceptarse oportunamente, hoy ya es totalmente inoperante y carece de posibilidades de continuación". 39

Las tratativas por reflotar el agrupamiento por parte del PC y el MUCS tras las elecciones cayeron en saco roto. El Plenario del MUCS de junio 1960 resolvió promover un nuevo plenario del MOU, aun cuando ya aceptaban que el mismo se encontraba paralizado. La disolución fue un hecho en los meses siguientes cuando el gobierno reencauzó la normalización de la CGT a partir de la formación de la “Comisión de los 20" con la total exclusión del MUCS. ${ }^{40}$ En definitiva, el final del MOU se enmarcó en la disputa de dirigentes por la conducción del movimiento obrero y su parálisis fue interpretada a partir de la acción deliberada de la Mesa de "las 62", que trabó la unidad confiando en ser la "depositaria exclusiva de la representación de la clase obrera” (Marischi, 1960; 18).

\footnotetext{
36 "Mañana, miércoles 9, en Plaza Once, gran acto del Movimiento Obrero Unificado (MOU)" NP $\mathrm{n}^{\circ}$ $506,8 / 3 / 60$, p. 1

37 "Declaración del Comité Ejecutivo del Partido Comunista con motivo del golpe militar palaciego" $N P \mathrm{n}^{\circ} 508,22 / 3 / 60$, p. 3

38 "El balance de los resultados de las elecciones del 27 de marzo" NE año XII, no 3, abril 1960, p. 202

39 “Plenario Nacional de las 62 Organizaciones. Mayo 20 de 1960". ASASG-UTDT C1-517. 00077

40 "El plenario sindical” NP n 544, 29/11/60, p. 6
} 


\section{Ezequiel Patricio Murmis}

\section{Conclusiones}

La política de acercamiento al peronismo que se delineó a partir de 1955 tenía un sustento general en la definición programática orientada hacia la revolución democrático-burguesa junto a diversos sectores democráticos y progresistas. Aquello que se pretendía concretar a nivel político, sintetizado en la apuesta por formar un Frente Democrático Nacional hacia la formación de un Gobierno de coalición democrática, se buscó llevar a cabo en los sindicatos a partir del establecimiento de una política de acción unitaria junto a los diversos sectores del movimiento obrero para la conquista de sus reivindicaciones.

La alianza entre comunistas y peronistas en la arena sindical fue posible, en primer término, por ese encuadramiento político. No obstante, el mismo no alcanza para explicarla. Los reiterados llamados del PC para concretarla en todo el período de la Resistencia solo fueron respondidos cuando los sectores peronistas lo habilitaron. El primer caso fue en la Comisión Intersindical y en las 62 Organizaciones, cuando la acción conjunta se revelaba necesaria para imponerse ante el llamado "sindicalismo libre" en 1957-1958; el segundo, como hemos visto, en el MOU de 1959-1960.

La derrota del movimiento obrero, el incremento represivo y el quiebre del acuerdo entre el gobierno y el peronismo fueron algunos de los factores coyunturales que hicieron posible el nuevo acercamiento. La ilegalización del PC fue también un aspecto que emparentó a ambos sectores en el camino de la exclusión institucional, más no agota los elementos para comprender esta alianza. Es necesario completar el cuadro poniendo en la balanza el peso específico adquirido por el sindicalismo comunista en el período.

Uno de los aspectos novedosos del período es la reubicación del comunismo en los sindicatos luego de una década de hegemonía peronista. Su crecimiento a partir de la conquista de direcciones sindicales, el armado de agrupamientos y su intervención en los principales conflictos obreros le permitieron ocupar un lugar insoslayable en el mapa de las direcciones obreras. Aun siendo un sector con menos influencia que el peronismo mayoritario, se trató de un polo significativo para enfrentar al gobierno de Frondizi.

Ahora bien, el repaso de esta relación muestra que, si para el PC el peronismo era un aliado estratégico, para el peronismo el PC era apenas un aliado táctico. Los lazos de la alianza demostraron ser endebles cuando el sector peronista rompió el MOU luego del golpe asestado al gobierno con el triunfo del voto blanco en las elecciones legislativas de 1960. La coincidencia entre el final del MOU y la conformación de la “Comisión de los 20" para la normalización de la CGT evidenció una táctica que el sindicalismo peronista desarrolló en la década siguiente: golpear para negociar.

La experiencia de acción conjunta en el MOU fue un fracaso a los ojos comunistas en tanto las pujas entre dirigencias frenaron la posibilidad de construir un comando 


\section{EI Partido Comunista en el Movimiento Obrero Unificado: una alianza con el sindicalismo peronista (1959-1960)}

único y centralizado de dirección que reemplazara a la CGT intervenida. No obstante, la política de acercamiento al peronismo continuó en los años siguientes, orientada bajo el diagnóstico del "giro a la izquierda del peronismo" en 1962: será cuestión de analizar en futuros trabajos la forma en que ello operó en el movimiento obrero.

De todos modos, este avance de investigación permite repensar la forma en que se interpretó el quiebre entre "vieja izquierda" y "nueva izquierda" producido en los '60 y '70. En definitiva, entendida como conjunto, el accionar y razón de ser de la "nueva izquierda" en estas décadas pareció basarse en el intento por resolver la cuestión de cómo hacer la revolución (nacional, antiimperialista, socialista, según la variante política que se trate) con las masas ya hegemonizadas por el peronismo; es decir, fue protagonista de lo que Altamirano (2001) denominó como una "situación revisionista" del vínculo entre los idearios de izquierdas y la clase obrera, en donde los polos principales de la cuestión eran, claro está, comunismo/socialismo y peronismo. En la investigación en torno a la morfología de la "nueva izquierda" se construye un juego de oposiciones en el que esta asume una serie de características contrastantes con la "vieja", al tiempo que elabora un discurso sobre "lo otro". En los sentidos construidos, una de las premisas fundamentales para interpretar a la "vieja izquierda" es la distancia entre el PC y la clase obrera en sentido amplio, en una fractura que puede ubicarse en 1946 y que parece verse como una herida histórica basada en el fracaso por conquistar a la clase obrera ante el avance del peronismo; se trata de una imagen que sobrevuela las lecturas del pasado como la cruz que cargó la "vieja izquierda", como el símbolo de la desconfianza de la militancia sesentista frente a la estructura rígida del representante soviético en el Sur que habría actuado siguiendo un manual teórico mientras las masas que pretendía conducir le daban la espalda.

El estudio de esta experiencia particular entre estos dos sujetos sociales, el partido y la clase obrera organizada, nos permite advertir que el surgimiento de nuevas agrupaciones que cuestionaron el programa del PC, sus modos de conducción, su relación con Moscú o su interpretación del peronismo, no puede explicarse sobre la base de un esquema estático anclado en el vínculo entre esos dos sujetos en 1946. La participación del PC en el MOU (y no sólo en él, sino también en la Comisión Intersindical y las 62 Organizaciones, mismo el "caso Real" de 1952 o el voto conjunto en diversas elecciones) sirve para demostrar que el partido reorientó sus acciones y concretó alianzas con el peronismo: es decir, que el partido también atravesó y fue sujeto de una "situación revisionista" del fenómeno peronista, con lo cual habría que pensar las fracturas y conflictos principalmente en función del programa, los modos de conducción internos y el tipo de revolución pregonado por el comunismo en la Argentina. En definitiva, en adelante podría profundizarse esta hipótesis analizando el surgimiento de la "nueva izquierda" más allá de los acercamientos del PC al peronismo en los distintos terrenos de intervención. 


\section{Ezequiel Patricio Murmis}

\section{Bibliografía}

Acha, O. (2008) Las huelgas bancarias, de Perón a Frondizi (1945-1959). Buenos Aires: CCC.

Altamirano, C. (2001) Peronismo y cultura de izquierda. Buenos Aires: Temas Grupo Editorial.

Camarero, H. (2014) “Tras las huellas de una ilusión: el Partido Comunista argentino y sus planteos del Frente Democrático Nacional (1955-1963)" Archivos de historia del movimiento obrero y la izquierda, año III, nํ⒌

Chiarini, S. y Portugheis, E. (2014) Plan CONINTES. Represión política y sindical. Buenos Aires: Ministerio de Justicia y Derechos Humanos de la Nación. Secretaría de Derechos Humanos. Archivo Nacional de la Memoria.

Gazzera, Miguel y Ceresole Norberto (1970) Peronismo: autocrítica y perspectivas Buenos Aires: Descartes.

Gilbert, I. (2009) La Fede alistándose para la revolución. La Federación Juvenil Comunista 1921-1995. Buenos Aires: Sudamericana.

Izquierdo, Roberto (2018) “"Dirigidos desde afuera». Los obreros del tabaco en la segunda fase de la Resistencia (1958-1959)”. Ponencia presentada en II Jornadas internacionales de historia del movimiento obrero y la izquierda, Buenos Aires.

James, D. (2010) Resistencia e integración. El peronismo y la clase trabajadora argentina, 1946-1976. (1990) Buenos Aires: Siglo XXI.

Marischi, V. (1958) La lucha de los comunistas por la unidad sindical del proletariado argentino. Buenos Aires: Anteo.

Marischi, V. (1960) ¡Hoy más que nunca! ¡Unidad sin discriminaciones para derrotar a los enemigos de la clase obrera y el pueblo! Buenos Aires: Anteo.

Murmis, E. (2018) "El Partido Comunista en los albores de la radicalización política en Argentina: estrategia, militancia sindical y antiterrorismo entre 1955 y 1959" Archivos de historia del movimiento obrero y la izquierda, año VII, n 13.

Murmis, E. (2020) “El sindicalismo comunista en la reorganización del movimiento obrero: hacia la formación del Movimiento de Unidad y Coordinación Sindical (MUCS) en 1958-1959", el@tina, vol. 18, nº 72. 


\section{EI Partido Comunista en el Movimiento Obrero Unificado: una alianza con el sindicalismo peronista (1959-1960)}

Peralta Ramos, M. (1973) Acumulación de capital y crisis política en la Argentina (1930-1974). Buenos Aires: Siglo XXI.

Rodríguez Lamas, D. (1984) La presidencia de Frondizi, Buenos Aires: CEAL.

Rodríguez Lamas, D. (1985) La Revolución Libertadora, Buenos Aires: CEAL.

Rotondaro, R. (1974) Realidad y cambio en el sindicalismo, Buenos Aires: Pleamar.

Rupar, B. (2018) “Cuando la táctica política se va transformando en estrategia: el giro en el Partido Comunista Argentino a fines de la década de 1950" Nuevo Mundo Mundos Nuevos [En ligne], Questions du temps présent, mis en ligne le 14 juin 2018, $\begin{array}{lllll}\text { consulté } & \text { le } & 15 & \text { juillet } & 2019 .\end{array}$ http://journals.openedition.org/nuevomundo/72176

Salas, E. (1990) La resistencia peronista: la toma del frigorífico Lisandro de la Torre, Buenos Aires: CEAL.

Sánchez, M. (2018) Los comunistas en la Unión Ferroviaria 1955-1968, Buenos Aires: Biblos.

Schneider, A. (2005) Los compañeros. Trabajadores, izquierda y peronismo, 19551973. Buenos Aires: Imago Mundi.

Senén González, S. (1971) El sindicalismo después de Perón, Buenos Aires: Galerna.

Tortti, M. C., (2012) "Soluciones: una experiencia de acercamiento entre el peronismo y la izquierda durante la campaña por el voto en blanco en 1960" Políticas de la memoria, nํ10-11-12, verano 2011-2012, Buenos Aires.

Tortti, M. C. (2014) "La nueva izquierda argentina. La cuestión del peronismo y el tema de la revolución”, en Tortti, M. C. (dir.), La nueva izquierda argentina (19551976). Socialismo, peronismo y revolución. Rosario: Prohistoria.

Zorrilla, R. (1974) Estructura y dinámica del sindicalismo argentino, Buenos Aires: La Pléyade.

Recibido: 21/07/2020

Evaluado: 07/09/2020

Versión Final: 24/09/2020 